\title{
Proximal Humeral Fractures: The Choice of Treatment
}

\author{
Stig Brorson and Henrik Palm
}

\subsection{Aim of Treatment}

The overall aim of shoulder fracture treatment is to reduce pain and regain the best possible function. Most patients do not regain previous shoulder function, some patients had an impaired shoulder function prior to the injury, and some patients suffer persistent pain, whether treated surgically or non-surgically.

Generally, pain-free function at shoulder level should be the goal of treatment, allowing daily activities. The achievable treatment result may vary widely and the aim of treatment should be part of the shared decision-making.

Most proximal humeral fractures eventually heal, and non-union is seen in only $1.1 \%$ of all fractures [1]. However, malunion is inevitable when displaced fractures are treated non-operatively in adults. This does not entail poor function or pain. Satisfactory patient-reported outcomes can often be obtained without restoring anatomy or replacing the joint with a prosthesis. Radiographic outcomes, range of motion and surgeon-administered outcome measures do not necessarily reflect the needs of the older patient suffering a shoulder fracture.

This chapter is a component of Part 2: Pillar I.

For an explanation of the grouping of chapters in this book, please see Chapter 1: 'The Multidisciplinary Approach to Fragility Fractures Around the World-An Overview'.

\footnotetext{
S. Brorson $(\bowtie)$

Zealand University Hospital, Køge, Denmark

Department of Clinical Medicine, University of Copenhagen, Copenhagen, Denmark e-mail: sbror@ regionsjaelland.dk

H. Palm

Bispebjerg University Hospital, Copenhagen, Denmark

Department of Clinical Medicine, University of Copenhagen, Copenhagen, Denmark e-mail: henrik.palm@ regionh.dk 


\subsection{Evidence and Literature}

The evidence base for the management of proximal humeral fractures has been weak until recently. The increasing amount of literature has so far mostly been unable to inform clinical practice, due to poor methodological quality with only about 3\% randomised clinical trials [2]. Consequently, different approaches can be found nationally, regionally and even between care providers at the same institution.

Although the latest Cochrane review [3] reported that surgery was not superior to non-surgical management for most proximal humeral fractures, less than $5 \%$ of the scientific literature on proximal humeral fractures deals with non-surgical treatment, while more than $70 \%$ deals with surgical treatment modalities [2]. Also, increased surgical activity has been reported [4] and in some parts of the world locking plates remains the gold standard treatment in displaced fractures among the elderly [5]. In recent years, the reverse total shoulder arthroplasty has gained popularity, but strong evidence has still to support this practice.

In the following paragraphs, we outline recent evidence-based principles for the management of these difficult fractures.

\subsection{Epidemiology}

Proximal humeral fractures are common and account for 4 to $6 \%$ of all human fractures [6]. Among the non-vertebral fractures, they are third only to the wrist and hip fractures and, like these, are closely associated with osteoporosis. The lifetime risk is $13 \%$ for a woman aged more than 50 years and around half of the patients have sustained a previous fracture [7]. A three-fold increase in incidence has been reported between 1970 and 2002 [8] and the incidence in women aged more than 80 years is as high as 520/100,000 per year [9] but seems to have stabilised in recent years [10].

Previously, it was believed that most proximal humeral fractures were minimally displaced [11]. However, recent epidemiological studies have unequivocally reported that most fractures are displaced $[6,12,13]$ and the complexity of the fractures seems to increase with advanced age [14].

\subsection{Fracture Classification}

Proximal humeral fractures have been classified since the earliest known medical texts [15]. From 1970 the most commonly used classification system for proximal humeral fractures has been the Neer classification [11] followed by the AO classification [16]. Both classification systems describe morphological aspects of the fracture anatomy in an ordinal framework aiming to support diagnostics, treatment and prognostics.

The Neer classification (Fig. 10.1) is based on the description of four anatomical segments of the proximal humerus, as they appear on plain 


\section{Part 3 Part 4 Part}

2
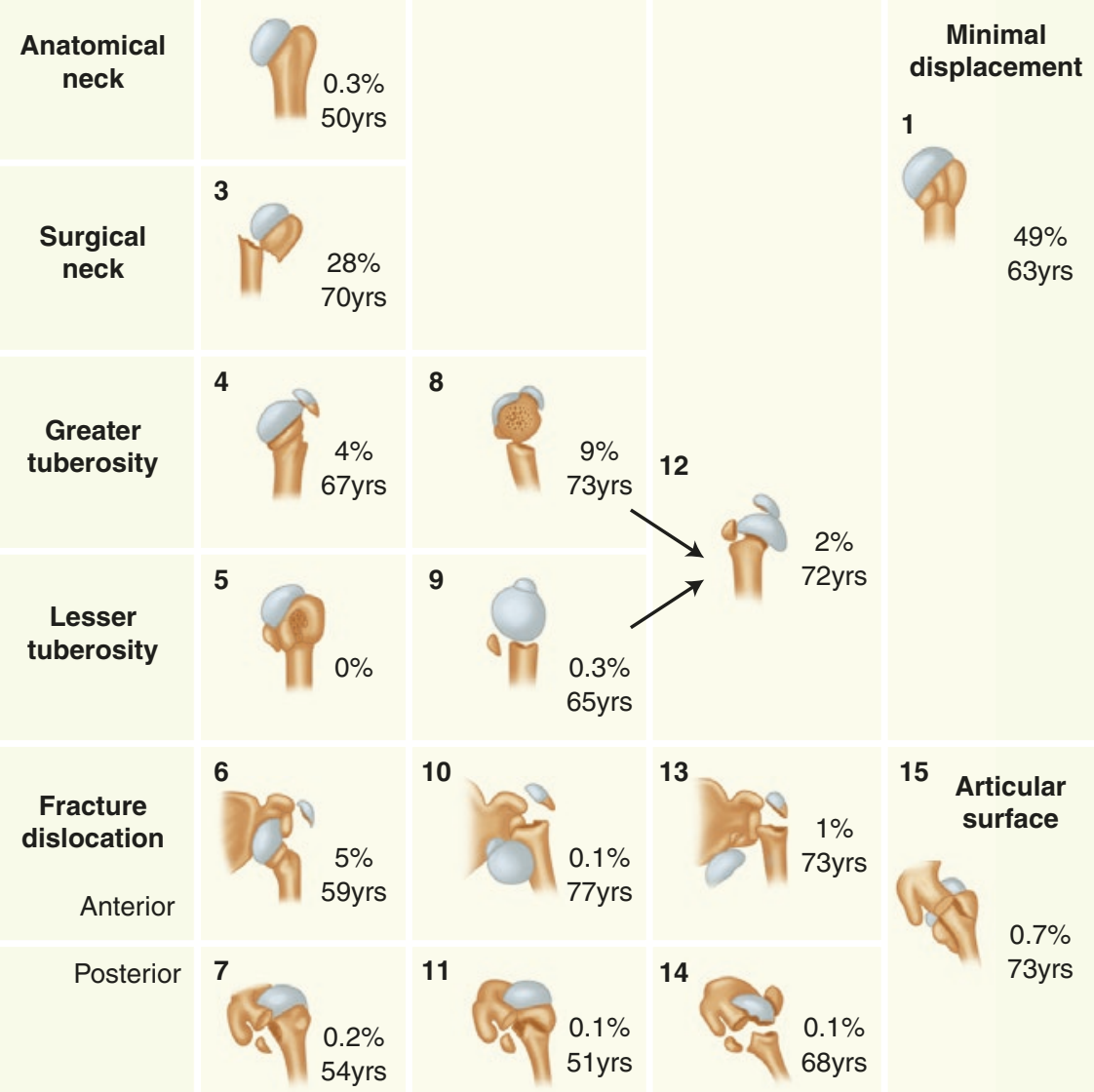

10

13

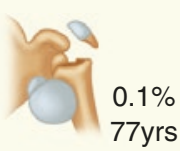

11

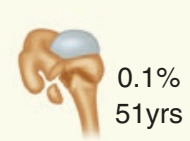

14

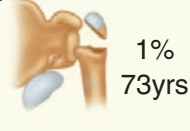

$73 y r s$

Fig. 10.1 Neer's classification with prevalence and the average age in each category. (Reproduced with permission from Acta Orthop)

anterior-posterior radiographs: (1) the humeral shaft, (2) the articular part of the humeral head, (3) the greater tuberosity and (4) the lesser tuberosity. If any of the four segments are displaced more than $1 \mathrm{~cm}$ or angulated more than $45^{\circ}$, the fracture is considered displaced, while all other fractures are categorised as minimally displaced fractures regardless of the number of fracture lines. According to the number of displaced segments, the fractures are termed 2-part, 3-part or 4-part.

This description is further qualified according to the involved segments, for example, 2-part surgical neck fracture (Fig. 10.2a), 3-part greater tuberosity fracture 

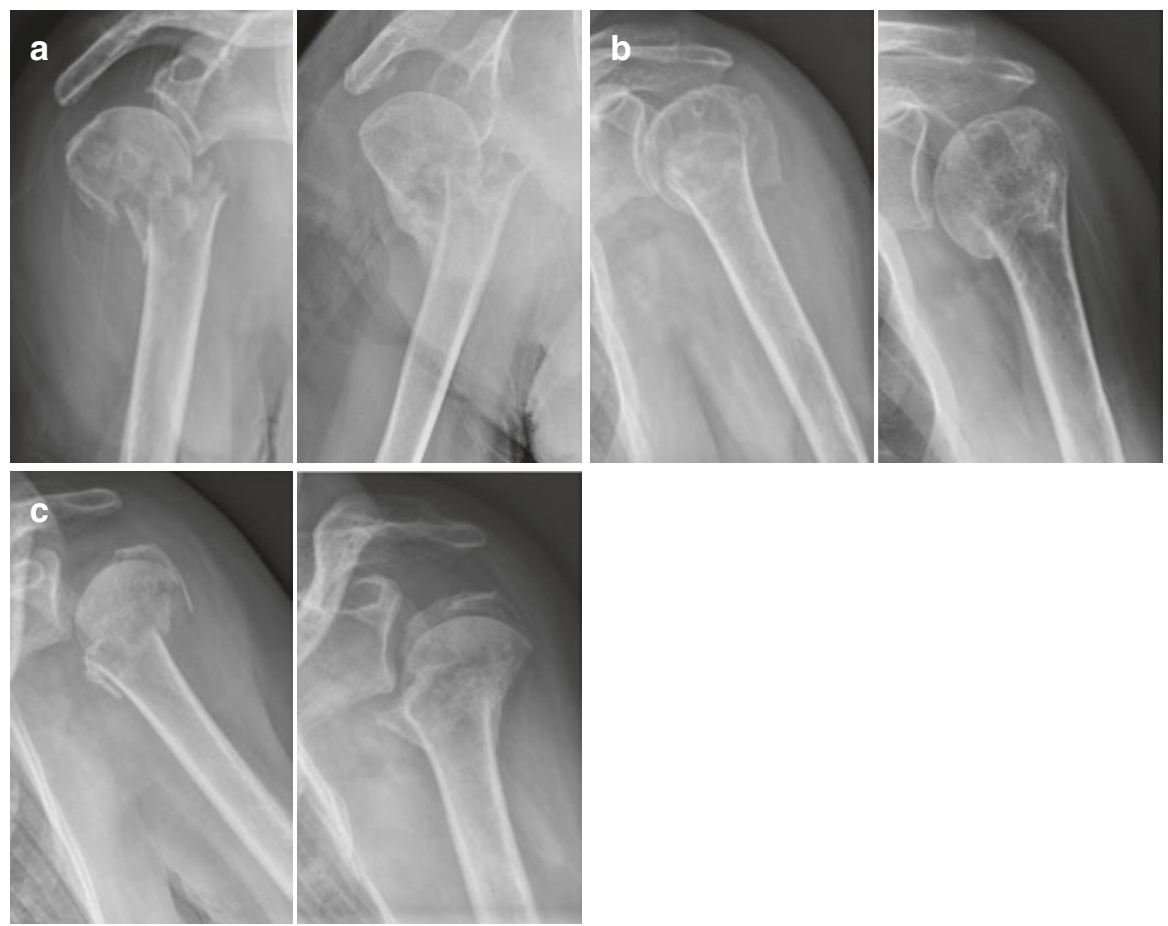

Fig. 10.2 Non-surgical healing of different types of proximal humeral fractures. (a) Displaced 2-part fracture of the 'surgical neck' treated non-surgically in an 81-year-old female nursing home resident suffering severe Parkinson's disease. Radiographs at admission (left image) and at 3 months (right image). The patient was pain-free and mobilised in a walker. Good healing but severe malunion was seen after 3 months. (b) Displaced 3-part greater tuberosity fracture treated non-surgically in a healthy 75-year old female. Radiographs at admission (left image) and 6 months (right image). The patient was independent living and pain-free. A slight decrease in strength in above shoulder activities was found but the patient achieved a full range of motion. (c) Displaced 4-part fracture treated non-surgically in a 66-year old female. Radiographs at admission (left image) and 4 months (right image). The patient was a pain-free function at shoulder level and selfreliant in all daily activities

(Fig. 10.2b) or 4-part fracture involving all segments (Fig. 10.2c). Eighty-six percent of all proximal humeral fractures are either minimally displaced (49\%), 2-part surgical neck fractures $(28 \%)$ or 3-part greater tuberosity fractures $(9 \%)$ [6].

Additional information about fracture anatomy can be obtained by adding axillary radiographs, CT-scans or 3D-CT scans. Numerous observer studies have demonstrated poor agreement between and within observers using the Neer classification and the AO classification even on very basic observations of displacement and dislocation [17]. Thus, the value of the classification of proximal humeral fractures in clinical decision making and research remains a challenge. The different use of classifications might explain the discrepancies in results and recommendations. Moreover, it has been difficult to establish a translation between the two commonly used classification systems [18]. 
The integrity of the rotator cuff is rarely assessed in trauma imaging. With advanced age, the incidence of degenerative rotator cuff tears increases. The prognostic importance of concomitant rotator cuff lesions is not known.

\subsubsection{Minimally Displaced Fractures}

For clinical purposes, proximal humeral fractures are often simply divided into the two main groups explained earlier, the minimally displaced fractures and the displaced fractures.

There is consensus that minimally displaced fractures can be managed nonoperatively with short immobilisation in a sling followed by early exercises. Strong evidence is sparse, but randomised trials so far have reported the best results following early mobilisation initiated after 1 week [19-22].

\subsubsection{Displaced Fractures}

The optimal treatment of displaced proximal humeral fractures has been a matter of controversy for decades. Recommendations have changed over time according to patients' and surgeons' preferences and influenced by the interests of implant providers.

It has proved difficult to demonstrate any beneficial effect of surgery in randomised trials. An increasing number of trials have reported no difference in functional outcome between surgical and non-surgical management and surgery seems to cause an increased risk of subsequent supplemental surgery. A Cochrane review included almost 2000 patients from randomised trials and could not find any benefits of surgery compared to non-surgical management [3]. The studies included displaced 2-part, 3-part and 4-part fractures. No evidence-based recommendations cover fracture-dislocations, articular fractures and isolated tuberosity fractures.

\subsection{Treatment}

Based on age, comorbidity, functional demand, fracture pattern, bone and soft tissue quality and patient preferences a shared treatment decision can be achieved. Based on the high-quality evidence available [3] non-surgical management should be the treatment of choice in minimally displaced fractures as well as in displaced 2-, 3 and 4-part fractures in older patients. Management of articular surface fractures, fracture-dislocations and isolated tuberosity fractures is not covered by high-quality evidence and these fractures may benefit from surgery (Fig. 10.3).

The use of locking plates in displaced 2-part fractures cannot be recommended, as current high-quality evidence suggests no benefits compared to non-surgical management [23]. Head-preserving osteosynthesis with locking plates in complex fracture patterns and poor bone quality has been accompanied by high complication and reoperation rates $[24,25]$ and cannot be recommended. 


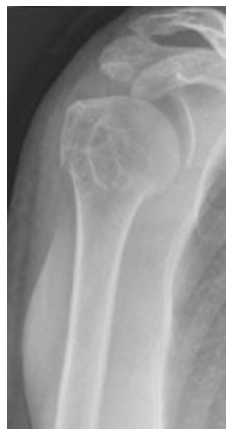

Non-surgical

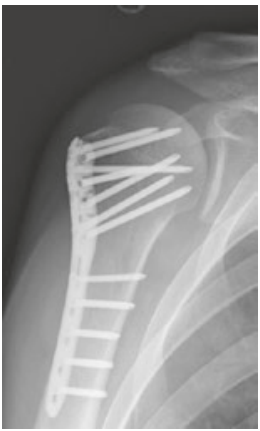

Locking Plate

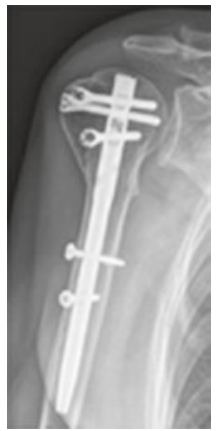

Locking Nail

Osteosyntheses
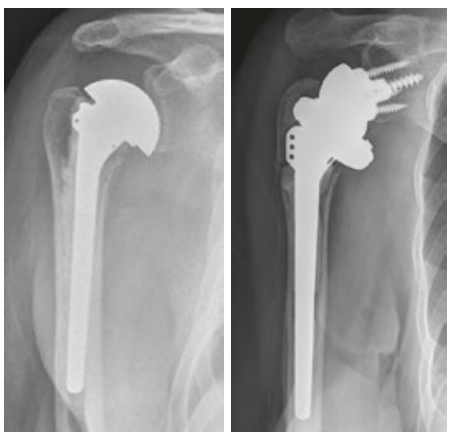

Hemi-Arthroplasty Reverse Arthroplasty

Prostheses

Fig. 10.3 The main treatment groups for proximal humeral fractures

If humeral head replacement with the use of a prosthesis is needed, a reverse total shoulder arthroplasty seems to lead to a better functional outcome than hemiarthroplasty [26]. The superiority of reverse shoulder arthroplasty compared to nonsurgical management has still to be demonstrated in high-quality studies, but results from the first randomised trial indicate that benefits are minimal in 3-, and 4-part fractures if patients are aged more than 80 years [27].

\subsubsection{Non-surgical Treatment}

Based on the available high-quality evidence [3] and the prevalence of fracture categories reported [6] more than $85 \%$ of all proximal humeral fractures can be managed without surgery. As previously mentioned, less than $5 \%$ of the scientific literature on proximal humeral fractures deals with non-surgical management [2] and more such studies are warranted, including a focus on pain relief, bandaging methods and systematic training programs.

Several randomised trials have however compared early and late mobilisation in non-surgical cases and reported less pain and better function when initiating training within the first week [20-22]. Early mobilisation can be recommended in most patients except in unstable 3- and 4- part fractures and in tuberosity fractures. In such cases, secondary displacement should be ruled out by outpatient visits, radiographs and controlled loading. The clinical effects of supervised training, home training or no structured training in older patients with proximal humeral fractures have been sparsely studied. Studies on time for the relief of pain are warranted, but our opinion is that most patients experience pain relief after 2 to 3 weeks. Progress in function and pain relief can be expected by 3 to 6 months after surgery. 


\subsubsection{Surgical Management}

Randomised trials and meta-analyses focusing on displaced 2-, 3- and 4-part fractures have been unable to demonstrate superiority of surgery compared to nonsurgical management [3]. There might however be a place for evidence-based surgery in older patients with fracture-dislocations, articular surface fractures and fractures with no contact between the bony fragments.

If surgical management is decided, osteosynthesis with a locking plate, or intramedullary nail can be an option if the humeral head can be preserved and tuberosity fixation is possible. If head-preserving surgery is not possible a joint prosthesis can be considered. Since the 1950s replacement of the humeral head with a shoulder hemiarthroplasty has been preferred, but within the last 20 years, the reverse total shoulder arthroplasty has gained increasing popularity as the outcome is less dependent on tuberosity fixation.

\subsection{Complications}

It is well known that complications can follow surgery. However, complications after non-surgical management are not systematically reported in the scientific literature. Most terms and definitions concern radiographic appearance of the fracture and their relation to functional outcome and patient satisfaction is poorly understood. Consensus-based and validated complication terms are needed [28]. Reported complications include shoulder stiffness, nonunion, malunion, avascular necrosis of the humeral head and persistent pain. Also, the implant itself can be mal-positioned primarily, or subsequently as a result of fracture collapse and/or avascular necrosis of the humeral head.

In cases of failed non-surgical management, as well as in failed osteosynthesis (Fig. 10.4), a reverse total shoulder arthroplasty represents a salvage option. Observational studies thereof have reported good pain relief and reasonable function regardless of tuberosity status.

\subsection{Outcome Assessment}

Large registry-based studies have reported low revision rates (about 4\%) after shoulder arthroplasty for fractures [29]. However, the patient-reported outcome has been less promising, suggesting a possible discrepancy between implant survival and patient satisfaction, as well as between the surgeons' and the patients' perspective on outcome [30].

Most clinical studies report patient outcomes using observer-administrated instruments like the Constant-Murley score [31]. These scoring systems are surgeonderived and tend to emphasise 'objective' measures like the range of motion and strength. It is our impression that patients' focus is more directed towards ADL (independent living) and social and emotional aspects of life (holding 

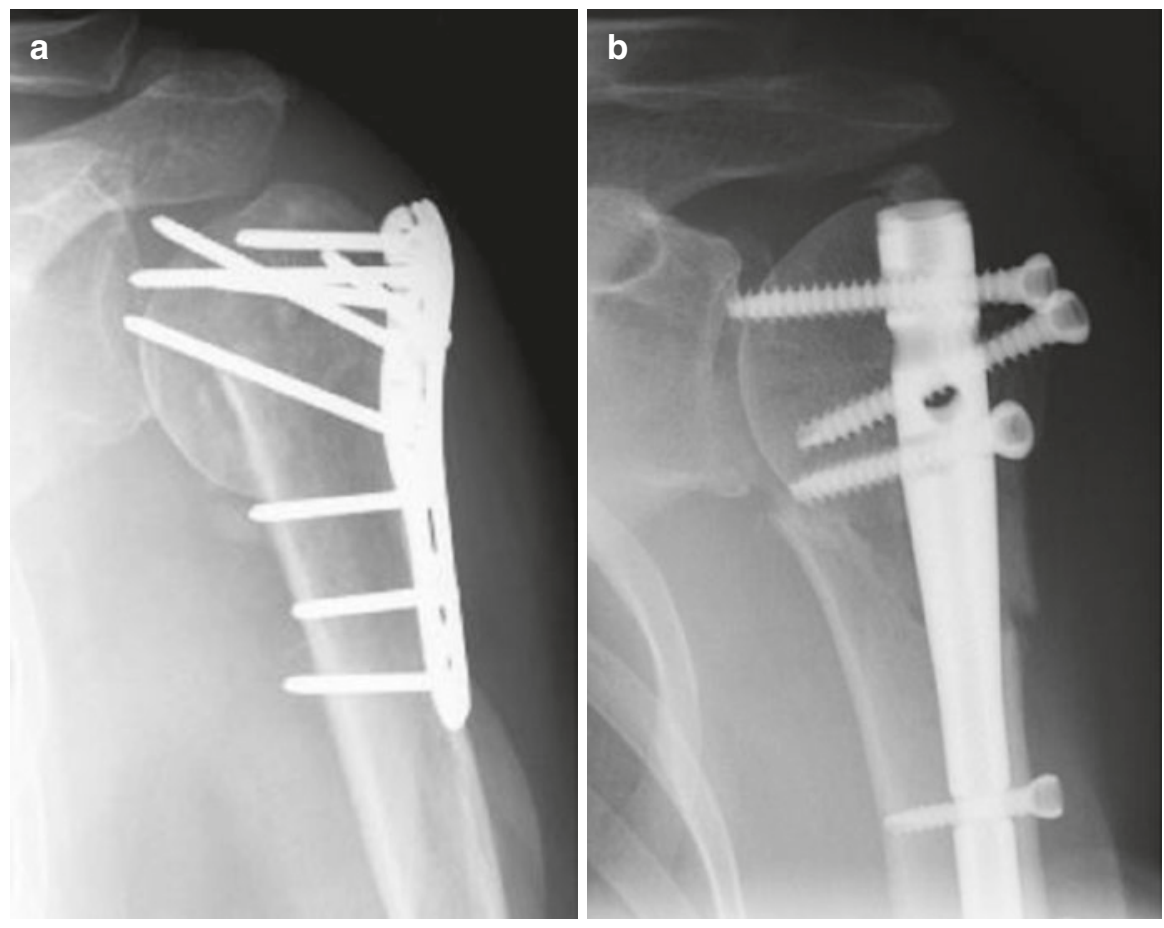

Fig. 10.4 Proximal humeral fracture complications subsequent to osteosynthesis. (a) Complications in a displaced 3-part greater tuberosity fracture managed with a locking plate. The humeral head has collapsed due to avascular necrosis. The screws are locked in the plate and subsequently penetrate the glenohumeral joint causing cartilage erosion and pain. (b) Complications in a displaced 2-part proximal humeral fracture fixated with a humeral locking nail. The fracture is mal-reduced and a locking screw is protruding into the glenohumeral joint

grandchildren, having dinner with family and friends, caring for disabled relatives). By focusing on 'objective' matters and radiographic appearance of fracture healing healthcare providers may fail to support important preferences of the patients.

Development of patient-related shoulder specific outcome assessment instruments (e.g. OSS, WOOS, ASES) and the use of generic quality of life measures (e.g. EQ-5D, SF-36) for patient evaluation have added to our knowledge of patient preferences. However, the shared decision making on treatment modalities and functional goals for the individual patient remains essential for healthcare providers.

\subsection{Conclusions}

There are many important aspects when treating an older patient with a proximal humeral fracture (Table 10.1).

Evidence-based management of proximal humeral fractures in the elderly should be based on high-quality clinical studies, as well as well-conducted systematic 
Table 10.1 Important points when treating elderly patients with a proximal humeral fracture

Non-surgical management should always be considered, as randomised trials have been unable to demonstrate benefits from surgery

Immediate surgical treatment is indicated only in patients with fracture-dislocations, articular fractures (7\% of all fractures) and in cases with neurovascular injury

Primary reverse total shoulder prosthesis seems superior to shoulder hemiarthroplasty in such cases

Shared decision making should include information on patient preferences, comorbidity, functional level, age and bone quality

A limited goal strategy should be agreed upon regardless of treatment choice. A pain-free and functional shoulder is a satisfactory outcome for most elderly patients

The radiographic outcome after displaced fractures managed non-surgically correlates poorly to functional outcome and patient satisfaction

Regaining social and emotional aspects of life is more important than radiographic appearance, range of motion and strength

Passive exercises should begin within the first week after injury

The evidence base for rehabilitation and different training regimens is poor

Proximal humeral fractures are among the typical osteoporotic fractures and elderly patients should be examined for osteoporosis

reviews and meta-analyses. Long term follow-up data on benefits and harms should be provided by national and international registries. The implementation of evidence-based recommendations should be facilitated by national, regional and local guidelines and validated algorithms based on the best available evidence. Resource allocation for patient care and research should be guided by the best evidence and the need for additional knowledge.

Patient preferences should be included at all levels of decision making from the design of research protocols to the development of patient-derived outcome measures. Not least, the treatment strategy for the individual older patient in the everyday clinic should be decided with the patient and relatives, and based on patient preferences, comorbidity, functional level, age and bone quality.

\section{References}

1. Court-Brown CM, McQueen MM (2008) Nonunions of the proximal humerus: their prevalence and functional outcome. J Trauma 64(6):1517-1521

2. Slobogean GP, Johal H, Lefaivre KA, MacIntyre NJ, Sprague S, Scott T, Guy P, Cripton PA, McKee M, Bhandari M (2015) A scoping review of the proximal humerus fracture literature. BMC Musculoskelet Disord 16:112

3. Handoll HH, Brorson S (2015) Interventions for treating proximal humeral fractures in adults. Cochrane Database Syst Rev (11):CD000434

4. Khatib O, Onyekwelu I, Zuckerman JD (2014) The incidence of proximal humeral fractures in New York State from 1990 through 2010 with an emphasis on operative management in patients aged 65 years or older. J Shoulder Elb Surg 23(9):1356-1362

5. Klug A, Gramlich Y, Wincheringer D, Schmidt-Horlohé K, Hoffmann R (2019) Trends in surgical management of proximal humeral fractures in adults: a nationwide study of records in Germany from 2007 to 2016. Arch Orthop Trauma Surg 139(12):1713-1721 
6. Court-Brown CM, Garg A, McQueen MM (2001) The epidemiology of proximal humeral fractures. Acta Orthop Scand 72(4):365-371

7. Johnell O, Kanis J (2005) Epidemiology of osteoporotic fractures. Osteoporos Int 16(Suppl 2):S3-S7

8. Palvanen M, Kannus P, Niemi S, Parkkari J (2006) Update in the epidemiology of proximal humeral fractures. Clin Orthop Relat Res 442:87-92

9. Court-Brown CM, Clement ND, Duckworth AD, Aitken S, Biant LC, McQueen MM (2014) The spectrum of fractures in the elderly. Bone Joint J 96-B(3):366-372

10. Kannus P, Niemi S, Sievänen H, Parkkari J (2017) Stabilized incidence in proximal humeral fractures of elderly women: nationwide statistics from Finland in 1970-2015. J Gerontol A Biol Sci Med Sci 72(10):1390-1393

11. Neer CS 2nd (1970) Displaced proximal humeral fractures. I. Classification and evaluation. J Bone Joint Surg Am 52(6):1077-1089

12. Roux A, Decroocq L, El Batti S, Bonnevialle N, Moineau G, Trojani C, Boileau P, de Peretti F (2012) Epidemiology of proximal humerus fractures managed in a trauma center. Orthop Traumatol Surg Res 98(6):715-719

13. Tamai K, Ishige N, Kuroda S, Ohno W, Itoh H, Hashiguchi H, Iizawa N, Mikasa M (2009) Four-segment classification of proximal humeral fractures revisited: a multicenter study on 509 cases. J Shoulder Elb Surg 18(6):845-850

14. Bahrs C, Stojicevic T, Blumenstock G, Brorson S, Badke A, Stöckle U, Rolauffs B, Freude T (2014) Trends in epidemiology and patho-anatomical pattern of proximal humeral fractures. Int Orthop 38(8):1697-1704

15. Brorson S (2013) Fractures of the proximal humerus. Acta Orthop Suppl 84(351):1-32

16. Marsh JL, Slongo TF, Agel J, Broderick JS, Creevey W, DeCoster TA, Prokuski L, Sirkin MS, Ziran B, Henley B, Audigé L (2007) Fracture and dislocation classification compendium 2007: Orthopaedic Trauma Association classification, database and outcomes committee. J Orthop Trauma 21(10 Suppl):S1-S133

17. Brorson S, Hróbjartsson A (2008) Training improves agreement among doctors using the Neer system for proximal humeral fractures in a systematic review. J Clin Epidemiol 61(1):7-16

18. Brorson S, Eckardt H, Audigé L, Rolauffs B, Bahrs C (2013) Translation between the Neerand the AO/OTA-classification for proximal humeral fractures: do we need to be bilingual to interpret the scientific literature? BMC Res Notes 6:69

19. Carbone S, Razzano C, Albino P, Mezzoprete R (2017) Immediate intensive mobilization compared with immediate conventional mobilization for the impacted osteoporotic conservatively treated proximal humeral fracture: a randomized controlled trial. Musculoskelet Surg 101(Suppl 2):137-143

20. Hodgson SA, Mawson SJ, Saxton JM, Stanley D (2007) Rehabilitation of two-part fractures of the neck of the humerus (two-year follow-up). J Shoulder Elb Surg 16(2):143-145

21. Kristiansen B, Angermann P, Larsen TK (1989) Functional results following fractures of the proximal humerus. A controlled clinical study comparing two periods of immobilization. Arch Orthop Trauma Surg 108(6):339-341

22. Lefevre-Colau MM, Babinet A, Fayad F, Fermanian J, Anract P, Roren A, Kansao J, Revel M, Poiraudeau S (2007) Immediate mobilization compared with conventional immobilization for the impacted nonoperatively treated proximal humeral fracture. A randomized controlled trial. J Bone Joint Surg Am 89(12):2582-2590

23. Launonen AP, Sumrein BO, Reito A, Lepola V, Paloneva J, Jonsson KB, Wolf O, Ström P, Berg HE, Felländer-Tsai L, Jansson KÅ, Fell D, Mechlenburg I, Døssing K, Østergaard H, Märtson A, Laitinen MK, Mattila VM, as the NITEP group (2019) Operative versus non-operative treatment for 2-part proximal humerus fracture: a multicenter randomized controlled trial. PLoS Med 16(7):e1002855

24. Brorson S, Rasmussen JV, Frich LH, Olsen BS, Hróbjartsson A (2012) Benefits and harms of locking plate osteosynthesis in intraarticular (OTA Type C) fractures of the proximal humerus: a systematic review. Injury 43(7):999-1005 
25. Brorson S, Frich LH, Winther A, Hróbjartsson A (2011) Locking plate osteosynthesis in displaced 4-part fractures of the proximal humerus. Acta Orthop 82(4):475-481

26. Sebastia-Forcada E, Lizaur-Utrilla A, Cebrian-Gomez R, Miralles-Muñoz FA, Lopez-Prats FA (2017) Outcomes of reverse total shoulder arthroplasty for proximal humeral fractures: primary arthroplasty versus secondary arthroplasty after failed proximal humeral locking plate fixation. J Orthop Trauma 31(8):e236-e240

27. Lopiz Y, Alcobía-Díaz B, Galán-Olleros M, García-Fernández C, Picado AL, Marco F (2019) Reverse shoulder arthroplasty versus nonoperative treatment for 3- or 4-part proximal humeral fractures in elderly patients: a prospective randomized controlled trial. J Shoulder Elb Surg 28(12):2259-2271

28. Brorson S, Alispahic N, Bahrs C, Joeris A, Steinitz A, Audigé L (2019) Complications after non-surgical management of proximal humeral fractures: a systematic review of terms and definitions. BMC Musculoskelet Disord 20(1):91

29. Brorson S, Salomonsson B, Jensen SL, Fenstad AM, Demir Y, Rasmussen JV (2017) Revision after shoulder replacement for acute fracture of the proximal humerus. Acta Orthop 88(4):446-450

30. Amundsen A, Rasmussen JV, Olsen BS, Brorson S (2019) Low revision rate despite poor functional outcome after stemmed hemiarthroplasty for acute proximal humeral fractures: 2,750 cases reported to the Danish Shoulder Arthroplasty Registry. Acta Orthop 90(3):196-201

31. Constant CR, Murley AH (1987) A clinical method of functional assessment of the shoulder. Clin Orthop Relat Res 214:160-164

Open Access This book is licensed under the terms of the Creative Commons AttributionNonCommercial-NoDerivatives 4.0 International License (http://creativecommons.org/licenses/ by-nc-nd/4.0/), which permits any noncommercial use, sharing, distribution and reproduction in any medium or format, as long as you give appropriate credit to the original author(s) and the source, provide a link to the Creative Commons license and indicate if you modified the licensed material. You do not have permission under this license to share adapted material derived from this book or parts of it.

The images or other third party material in this book are included in the book's Creative Commons license, unless indicated otherwise in a credit line to the material. If material is not included in the book's Creative Commons license and your intended use is not permitted by statutory regulation or exceeds the permitted use, you will need to obtain permission directly from the copyright holder.

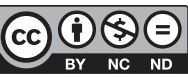

